\title{
Empirical Analysis of Relationship between Per Capita Health Expenditure and Economic Growth Based on Vector Autoregressive Model (VAR) in Mongolia
}

\author{
Uranbileg Bayarbat, Yibing Li* \\ Department of Social and Management Pharmacy, International Pharmaceutical Business School, China Pharmaceutical University, \\ Nanjing, China \\ Email: *zgykdxlyb@sina.com
}

How to cite this paper: Bayarbat, U. and Li, Y.B. (2020) Empirical Analysis of Relationship between Per Capita Health Expenditure and Economic Growth Based on Vector Autoregressive Model (VAR) in Mongolia. Theoretical Economics Letters, 10, 154-168.

https://doi.org/10.4236/tel.2020.101010

Received: January 10, 2020

Accepted: February 16, 2020

Published: February 19, 2020

Copyright $\odot 2020$ by author(s) and Scientific Research Publishing Inc. This work is licensed under the Creative Commons Attribution International License (CC BY 4.0).

http://creativecommons.org/licenses/by/4.0/

\begin{abstract}
The present research aimed to study the dynamic correlation between per capita health expenditure (PCHE) and economic growth in Mongolia. The data from the period of 1993-2018 were used. A Vector Autoregressive (VAR) model was established between per capita gross domestic product (PGDP) and PCHE. Variance decomposition as well as impulse response function was used to analyze the dynamic relationship among variables. The results revealed that correlation was found between PCHE and PGDP with obvious one-way Granger causality. Moreover, the results showed that economic development had positive impact on PCHE growth for 1 - 3 (short term) years in Mongolia. However, the response of the two variables was gradually eradicated in the long term by impulse response function. The contribution rate of PGDP on PCHE increased from $0 \%$ to $18.14 \%$ by six periods. This study recommended that Mongolian policymakers not only increase the budget to the health but rather oversee the budget spending, increase public health expenditure and improve private health insurance system, which leads to the upgraded national health and can reduce personal health burden.
\end{abstract}

\section{Keywords}

Health Expenditure, VAR Model, Impulse Response Function, Variance Decomposition, Mongolia

\section{Introduction}

The fundamental relationship between per capita health expenditure (PCHE) 
1and economic growth is a topic of general concern for policy makers and economists. A common result of most researches (Newhouse [1], Barro and Sala-i-Martin [2] and Kleiman [3]) suggested that economic growth is one of the significant factors influencing the health expenditure. For empirical analysis of these kinds of relationships in previous literature, unit root test, co-integration and VAR models are important impacts. Hansen and King [4], Gerdtham and Lothgren [5], McCoskey and Selden [6] and Blomqvist and Carter [7] used panel unit root test and co-integration test for studying the relationship between variables. With the development of modern countries' economies, per capita gross domestic product (PGDP) has also increased, and the demand for medical services by population has further increased, which resulted in an increase in PCHE [8]. In Mongolia, from 1990 to 2019, the annual growth rate of GDP has raised up to $7.2 \%$ [9]. In recent years, although the health budget has increased by nearly five times, the ratios of PCHE on the GDP have steadily decreased from $4.6 \%$ in 2000 to $3.1 \%$ in 2017 , which is less than $5 \%$ recommended by WHO [10]. However, according to some research findings, despite an increasing amount of health expenditure and the high coverage of the social health insurance (SHI) of the population in recent years in Mongolia, 5.5\% of households or 20,000 of the total population are suffered from catastrophic health expenditure. This evidence indicated the disadvantages of Mongolian health system such as inefficient spending of health financing on health care [11]. Although Mongolian economy is growing steadily for recent years, health care expenditure as share of GDP remains unchanged, moreover, vice versa tends to decline. Therefore, based on the above ground, the following questions are interesting to the research. There is a question of whether relationship exists between per capita health expenditure and per capita GDP in Mongolian case. Researchers emphasized (Chen Guoyong) [12] that the economic factors and population factors for PCHE are greater in the short term. Among them, PGDP has the greatest impact. Moreover, different income groups have different one-way causality patterns. In low- and middle-income countries, one-way causal relationships generally range from income to health, while in high-income countries, it is vice versa. Thus, according to the World Bank, Mongolia belongs as a middle-income country category. How does the economic growth impact on health expenditure in the short and long term? This study aims to analyze the correlation between per capita GDP and per capita health expenditure in the long and short term. Data covering the period 1993-2018 were obtained from the Statistical Office of Mongolia and Statistical Yearbook. To date, there is no study to analyze the relationship between health expenditure and economic growth in the Mongolian case by using VAR model.

\section{Literature Review}

The link between economic growth and health spending has been assessed by many types of studies such as Haldar [13] analyzed the association between 
economic growth and health expenses during 2008 in India by means of Granger Causality Analysis. It was revealed that there exist two-way causality association between health care spending and economic development. Similarly, Bukenya [14] defined the effect of health care expenses on the economic improvement of USA using VAR model. It was determined that health expenditure was accepted as a substantial indicator of economic development. Some of researchers also found similar results using the same methodology of regression model [15] [16] [17] [18] [19]. Besides this, Li Yi-bing [20] analyzed the relationship between economic development and health expenditure of people of China using VAR model in 2017. The findings exposed that there are two-way Granger causalities, impact of GDP on PCHE has both short-term and long-term effects. In addition, Chen Hong-hai [21] described the co-integration relationship among the variables. The real PCHE has a strong long-term relationship with the real PGDP while the elasticity of health service demand is 1.319. Zhou Zhaomei [22] obtained the results of economic growth and health expenditure by the comparison of The Organization for Economic of Co-operation and Development (OECD) He Bin's [23] found correlation between economic growth and health investment on the basis of VAR model and showed that the correlation between two variables was strongest, and the short term economic growth will promote health expenditures. Çetin and Ecevit [24] used panel data to analyze the impact of health on economic growth. The study included annual data from 15 OECD countries for the period 1990-2006 and analyzed share of public health expenditures in total health expenditures and other explanatory variables by a panel Ordinal Least Square (OLS) method. However, the results revealed that there was no any statistically significant relationship between health spending and the growth of economic. Besides this, Wang [25] investigated the total international medical expenses of 31 countries from 1986 to 2007 to assess the causal relationship between the growth of medical expenditure and economic growth. The estimation of the panel regression revealed that, health expenditure growth will stimulate economic growth; however, economic growth will decrease the health expenses. Serap Bedir [26] pointed out that when the economy grows, the proportion of medical expenditure to GDP will also rise resulting in a significant influence on GDP. Sghari and Hammami [27] examined the causality between per capita health expenditure and per capita GDP by employing panel data of 30 developing countries from 1975 to 2011. The result concluded there is a two-way Granger causality between two variables in selected countries.

Esteve and Zahonero [28] explored the long term correlation between per capita health expenditure and per capita national income by using Spanish annual data from 1960 to 2001. The results indicated that there was a co-integration relationship between per capita health expenditure and per capita GDP and economic growth elasticity of health expenditure of 1.54 , which considered that health had been determined as a luxury.

Keeping in view the review of literature and the importance of determining PCHE in order to make new policies and health budget, the current study was 
aimed to investigate the per capita expenditure of Mongolia country. The study collected data of 25 years of per capita expenditure and PGDP and analyzed it using VAR model. The study provides some significant correlation and meaningful suggestion for policy makers in order to make a balance between health expenditure and GDP and to improve the health outcome of population in Mongolia.

\section{Data and Methodology}

\subsection{Data}

The study was conducted in with regard to Mongolia country. Data regarding PCHE and PGDP of Mongolia of 25 years were collected and analyzed in this research. The PCHE data covering the period 1993-2018 were obtained from the Statistical information database and Statistical Yearbook of Mongolia, while data on PGDP for the same period were obtained from the statistical database of national account. In order to eliminate the impact of population change on total health expenditure, PCHE was selected as index. Two variables were analyzed using natural logarithms similar to empirical studies, while PGDP and PCHE were separately labeled as LNPGDP and LNPCHE in this study

\subsection{Methodology}

In order to analyze the correlation between per capita health expenditure and per capita GDP used the following main four steps of econometric methodology. First, before testing co-integration and VAR model requires all variables are (LNPGDP and LNPCHE) stationary. Thus, by employing unit root test including Phillips-Perron test (PP) [29] and Augmented Dickey Fuller (ADF) [30]. Second step, after stationary checks, we employed co-integration test to check whether there is exist a stable long-term relationship between PCHE and PGDP. To accomplish this test, the Johansen test and the Engle-Granger (EG) two-step test were employed. [31]. Third, in order to determine direction of causality between PCHE and PGDP was examined using causality test developed by Granger [32]. Granger causality test examines whether the past changes of PCHE or PGDP variables could explain the current change. To end, after checked co-integration, we need to establish VAR model proposed by Christopher A Sims [33]. By estimating the VAR analysis model in variance decomposition and impulse response function, can be able to determine the effect of PGDP's changes on PCHE.

\subsection{Vector Autoregressive Analysis}

The interrelationship between time series and the dynamic impact of random perturbation terms on variables to explain the impact on economic variables can be analyzed without economic theory [34] [35]. At the same time, VAR model can take into account the combined effects of different variables, without considering the multi collinearity problems that cross-sectional data often appear in 
regression [34]. The modeling idea of VAR model is to construct every exogenous variable as the lag function of endogenous variable (transformed to stationary). The expression of general vector autoregressive model is as follow:

$$
\begin{aligned}
Y_{t}= & A_{0}+A_{1} Y_{t}-1+A_{2} Y_{t-2}-2+\cdots+A_{p} Y_{t}-p \\
& +B_{1} X_{t}+\cdots+B_{q} X_{t}-q+U_{t}, \quad t=1,2, \cdots, T
\end{aligned}
$$

$Y_{t}$ is a k-dimensional endogenous variable vector, $X_{t}$ is an r-dimensional exogenous variable vector, $A_{0}, A_{1}, A_{2}, \cdots, A_{p}$ and $B_{1}, \cdots, B_{q}$ is a parameter matrix to be estimated, and $p$ and $q$ represent respectively. The lag order of the birth and exogenous variables, $T$ represents the number of samples, $U_{t}$ is a random disturbance, and the random disturbances can be related, but not related to their own lag values. Based on Koehler and Murphree [36], the Akaike information criterion (AIC) we choose the most fit $\operatorname{VAR}(p)$ model of lag order $\operatorname{VAR}(1)$ and the Schwarz Information Criterion (SIC) is a more criterion for this application.

\subsubsection{Impulse Response Function (IRF)}

The dynamic analysis of the established VAR model was carried out systematically following the methodology reported elsewhere [14]. IRF tracks the response of the present and upcoming values of each variable to the current value of one of the VAR errors in one unit, supposing that the error returns to zero in a subsequent period of time, and all other errors are equal to zero.

The $\operatorname{VAR}(P)$ model is represented by following equation

$$
Y_{t}=\left(I_{k}-\Phi_{1} L-\cdots-\Phi_{p} L^{p}\right)^{-1} \varepsilon_{t}=\left(L_{k}+\theta_{1} L+\cdots+\theta_{2} L_{2}+\cdots\right) \varepsilon_{t}
$$

The $\operatorname{VMA}(\infty)$ model can be used to represent the $\operatorname{VAR}(P)$ model, so the $\operatorname{VMA}(\infty)$ model can be expressed by Equation (7):

$$
Y_{t}=\left(I_{k}+\theta_{1} L+\cdots+\theta_{2} L_{2}+\cdots\right) \varepsilon_{t} \quad(t=1,2,3, \cdots, T)
$$

The i represents the variable of $Y_{t}$ can be shown by (Formula 8):

$$
Y_{i t}=\sum_{j-1}^{k}\left(\theta_{i j}^{(0)} \varepsilon_{i t}+\theta_{i j}^{(1)} \varepsilon_{i t-1}+\theta_{i j}^{(2)} \varepsilon_{i t-2}+\cdots\right)
$$

The response function of $Y_{i}$ caused by the pulse of $Y_{j}$ is

$$
\theta_{i j}^{(0)}, \theta_{i j}^{(1)}, \theta_{i j}^{(2)}, \theta_{i j}^{(3)}, \cdots
$$

Therefore, the cumulative response function of $Y_{i}$ caused by the pulse of $Y_{j}$ is:

$$
\sum_{(q-1)}^{\infty} \theta_{i j}^{(q)}
$$

The $i$-th row and the $j$-th column of $\Theta q$ are a function of $q$, which is recorded as:

$$
\theta_{i j}^{(q)}=\frac{\sigma Y_{i t+q}}{\sigma \varepsilon_{j t}}, q=0,1,2, \cdots,(t=1,2,3, \cdots, T)
$$

Equation (11) is called impulse response function, Assuming that the disturbance term in other periods is constant, this function represents the disturbance term of every unit added to the $j$-th variable in $t$ period, $Y_{i, t+q}$ produces a unit shock on $\varepsilon_{j t}$. 


\subsubsection{Variance Decomposition}

At last, this study perform variance decomposition analysis between PCHE and PGDP to determine the contribution of the impact of each structure to the change of endogenous variables, which can provide the relative degree of the impact of each disturbance on the endogenous variables in VAR model and variance decomposition was analyzed following the method of previous study [37]. Variance is often used to measure the contribution rate which is another way of studying the influence relationship between variables proposed by Christopher Simms in 1980 [33].

\section{Estimation, Results and Discussion}

\subsection{Unit Root Test}

The precondition of Granger causality test and VAR model is that the time series must be stable and check for the order integration of two variables, otherwise false regression may occur. The expression of two tests estimation is as follow:

$$
\Delta Y_{t}=\alpha_{0}+\alpha_{i} Y_{t-1}+\sum \beta_{i} \Delta Y_{t-1}+\varepsilon_{t}
$$

$Y$ indicates the variable; $\varepsilon_{t}$ is a stationary process; $\Delta$ is the first difference; $\alpha_{i}$ $(i=0$ and 1$)$ and $\beta_{i}(i=1,2, \cdots, \delta)$ shows constant coefficients. The integral order of time series variable can be defined by the second-order difference of single period lag and delta lag. The equation as follows:

$$
\Delta^{2} Y_{t}=\eta_{1} \Delta Y_{t-1}+\sum \mu_{i} \Delta^{2} Y_{t-i}+\varepsilon_{t}
$$

$\Delta^{2}$ is represent second difference, constant coefficients are showed by $\eta_{1}$ and $\mu_{i}$ (for $i=1,2, \cdots, \delta$ ). In this study for stabilize, ADF and PP test be used to Equation (1) and Equation (2).

The result in Table 1, we can see that both LNPGDP and LNPCHE are non-stationary in level series. For the first difference of LNPCHE and LNPGDP, the null hypothesis of the unit root is rejected. Thus, the results show that variables are integrated into the 1(1) sequence. Therefore, two variables can be used to the necessary conditions for establishing VAR model, Granger causality and co-integration test.

\subsection{Co-Integration Test}

The co-integration test is used to analyze the stable relationship between variables

Table 1. Unit root test results (ADF).

\begin{tabular}{cccccc}
\hline Variable & ADF & 1\% level & 5\% level & P value & Result \\
\hline LNPGDP & -2.169565 & -3.724070 & -2.986225 & 0.2214 & Non-stationary \\
$\Delta$ LNPGDP & -3.981060 & -3.737853 & -2.991878 & 0.0057 & Stationary \\
LNPCHE & -2.743801 & -3.724070 & -2.986225 & 0.0810 & Non-stationary \\
$\Delta$ LNPCHE & -4.907246 & -3.737853 & -2.991878 & 0.0007 & Stationary \\
\hline
\end{tabular}

${ }^{\star}$ Significant at $5 \%$ level. Note: $\Delta$ 1st difference Source: Statistical Year Book. 
for long-term. By testing whether the residual sequence of regression equation of a set of variables is stable, the existence of co-integration between dependent variables and explanatory variables can be found. Based on the ADF test, LNPCHE and LNPGDP variables were integrated sequence by $1(1)$ and non-stationary time series. Co-integration analysis is a modeling method on the basis of VAR of time series, which combines spatial structure with time dynamics. Co-integration analysis was performed using the methodology of the Engle-Granger (EG) [31] two-step test and Johansen (1988) [38] which explains the independent and dependent variables move together for the long term due to rejection of null hypothesis of $\mathrm{H}_{0}: r=0$ against $r \leq 1$ at $1 \%$ level. The Engle-Granger (EG) test explains how the dependent variables are changed by a $1 \%$ increase of the independent variable affect.

The results of Johansen Co-integration test are shown in Table 2. Without the assumption of co-integration, the trace statistic value is 10.94376, less than the critical value of 15.4947 , and the probability is 0.251 . The original hypothesis cannot be rejected, thus, the co-integration result suggests that a long-term relationship PCHE and PGDP seems do not exist in Mongolia. Similarly, Table 3 reveals no long term co-integration relationship between variables. Therefore, it can be further analyzed whether there is a short-term co-integration relationship between PCHE and PGDP.

This paper uses Engle-Granger (EG) two-step method. Using LNPGDP as independent variable and LNPCHE as dependent variable, OLS regression analysis was carried out. The results are as follows:

$$
\begin{gathered}
\text { LPCHE }=0.936448267635 * \text { LPGDP }+3.80842833334 \\
R 2=0.99 ; D W=0.932 ; P=0.0000
\end{gathered}
$$

According to results, with an increase of $1 \%$ in the ratio of GDP, the ratio of investment to health expenditure will increase by $3.808 \%$ and $0.93 \%$ show that PGDP has an influence on PCHE. This economic elasticity of health is less than 1. It indicates the health necessity good.

\subsection{Granger Causality Test}

The findings of ADF test show that both LNPGDP and LNPCHE are first-order

Table 2. Johansen test for trace statistics.

\begin{tabular}{ccccc}
\hline Hypothesized & Eigenvalue & T-Statistic & 0.05 Critical Value & Prob. ${ }^{* *}$ \\
\hline None & 0.348168 & 10.94376 & 15.49471 & 0.2150 \\
At most 1 & 0.027633 & 0.672523 & 3.841466 & 0.4122 \\
\hline
\end{tabular}

*Significant at $1 \%$ level.

Table 3. Johansen test for maximum eigenvalue test.

\begin{tabular}{ccccc}
\hline Hypothesized & Eigenvalue & T-Statistic & 0.05 Critical Value & Prob. $^{* *}$ \\
\hline None & 0.348168 & 10.27124 & 14.26460 & 0.1947 \\
At most 1 & 0.027633 & 0.672523 & 3.841466 & 0.4122 \\
\hline
\end{tabular}


monolithic. The standard Granger causality test determines whether the past change of one variable (PHE) helps to explain the predicted change of another variable (GDP), rather than the explanation provided by the PGDP change [35]. First, using ADF test [39] it was determined whether there is unit root to explore the stationary characteristics of PHE and PGDP time series. Second, to check co-integration test [27] [28], when if there is no existence of co-integration relationship between two variables we can establish VAR model [32]. The granger causality test equation as follows:

$$
\begin{aligned}
& \Delta Y_{t}=\alpha+\sum_{i=1}^{m} b_{I i} \Delta Y_{t-1}+\sum_{j=1}^{m} C_{1 j} \Delta Y_{t-1}+\varepsilon_{1 t} \\
& \Delta X_{t}=\beta+\sum_{i=1}^{m} b_{2 i} \Delta X_{t-i}+\sum_{j=1}^{m} c \Delta Y_{t-j}+\varepsilon_{2 t}
\end{aligned}
$$

There $\alpha$ and $\beta$ represent the intercept terms, $c, b, c, c_{1}, c_{2}, \cdots, c_{m}, y_{1}, y_{1}, \cdots, y_{m}$ are estimated coefficients, $m$ is optimal lag order, which is indicated by Schwarz information criterion (SIC). Based on Koehler and Murphree [36], the Akaike information criterion (AIC) we choose the most fit $\operatorname{VAR}(p)$ model of lag order $\operatorname{VAR}(1)$ and the SIC is a more criterion for this application. The null hypothesis is that $\mathrm{X}$ cannot reject Granger cause $\mathrm{Y}$ in Equation (4) where $\mathrm{H}_{0}: C_{1 j}=0$ for $j=1, \cdots, m$ is tested against $\mathrm{H}_{1}: C_{1 i} \neq 0$ and $\mathrm{Y}$ cannot reject Granger cause $\mathrm{X}$ in Equation (5) Which is showed by $\mathrm{H}_{0}: \eta_{2 j}=0$ for $j=1, \cdots, I$ is tested against $\mathrm{H}_{1}: \eta_{2 j} \neq 0$.

From Table 4, it can be concluded for the null hypothesis that GDP does not Granger cause PCHE, the null hypothesis is rejected with a significant level of $5 \%$. Whereas, it proposes that standard causality test cannot reject the null hypothesis because PCHE does not Granger cause economic growth for Mongolia. It can be explained that the change of PGDP growth is due to the increase in PCHE, while the change of PCHE growth is not the cause of the increase of PGDP. There is a one-way causality from GDP to PCHE for Mongolia.

\subsection{Estimation of VAR Model}

VAR method provides a useful approach for analyzing the wide correlation of system variables. It is widely used to explain the linear relationship between multiple time series variables. The relationship between time series and the dynamic influence of random disturbance on variables elucidates the influence of random disturbance on economic variables [35]. The results of VAR model are shown in Table 5, in the current situation, VAR model can be applied to emphasize the impact of changes in PCHE on PGDP in two ways: variance decomposition and followed by impulse response analysis. These statistics are more informative than the estimation of VAR model coefficients and $\mathrm{R}^{2}$ statistics. The results of VAR model typically go unreported. To this end, the estimated VAR can be used to calculate the percentage of each endogenous and to interpret the variables and provide evidence about the relative prominence of each random innovation to VAR variables [40]. 
Table 4. Granger causality test result.

\begin{tabular}{ccc}
\hline Null Hypothesis & F-Statistic & Prob. \\
\hline LNPGDP does not Granger Cause LNPCHE & 5.93733 & $0.0099^{*}$ \\
LNPCHE does not Granger Cause LNPGDP & 0.00932 & 0.9907 \\
\hline
\end{tabular}

Table 5. VAR model result.

\begin{tabular}{ccc}
\hline & $\mathrm{D}(\mathrm{LPCHE})$ & $\mathrm{D}(\mathrm{LPGDP})$ \\
\hline $\mathrm{D}(\mathrm{LPCHE}(-1))$ & -0.468229 & -0.401132 \\
& $(0.24060)$ & $(0.17984)$ \\
$\mathrm{D}(\mathrm{LPCHE}(-2))$ & {$[-1.94610]$} & {$[-2.23047]$} \\
& -0.368935 & -0.492583 \\
& $(0.21950)$ & $(0.16407)$ \\
$\mathrm{D}(\mathrm{LPGDP}(-1))$ & {$[-1.68080]$} & {$[-3.00225]$} \\
& 0.552936 & 0.212471 \\
$\mathrm{D}(\mathrm{LPGDP}(-2))$ & $(0.23871)$ & $(0.17843)$ \\
& {$[2.31635]$} & {$[1.19078]$} \\
& 0.607314 & 0.606401 \\
& $(0.26049)$ & $(0.19471)$ \\
& {$[2.33139]$} & {$[3.11432]$} \\
$\mathrm{C}$ & 0.087362 & 0.160878 \\
& $(0.04855)$ & $(0.03629)$ \\
& {$[1.79948]$} & {$[4.43328]$} \\
\hline & &
\end{tabular}

\subsection{Impulse Response Function}

As shown in Figure 1, there is evidence that economic growth has a positive impact on PCHE. Positive impacts on PGDP are described to increase the PCHE for up to two periods. Here the lag dependency declines strongly by the third period. Lag dependency is the weakest by the six periods and is sustained for several periods. The impact shocks tend to zero, reaching a convergent state. Figure 2 shows that the impact of per capita health expenditure on per capita GDP begins to decrease from positive to negative in the first period. But gradually increase from the second to six periods. Response of PGDP on PCHE reached up positive at six periods, but tended to further slowly declined by long term. In other words, economic growth leads to increase per capita health expenditure in short-term in Mongolia. The growth of GDP will improve the income of population. Thus, in this case, population will tend to more receive medical care service and more increase out-of-pocket payment on health.

\subsection{Variance Decomposition Analysis}

Table 6 shows the results of Variance Decomposition analysis. The findings explain that the contribution of PCHE in the first period is only affected by its 
Table 6. Variance decomposition of D(LNPCHE).

\begin{tabular}{cccc}
\hline Period & S.E. & D(LNPCHE) & D(LNPGDP) \\
\hline 1 & 0.114560 & 100.0000 & 0.000000 \\
2 & 0.128058 & 88.13119 & 11.86881 \\
3 & 0.136268 & 82.07660 & 17.92340 \\
4 & 0.137121 & 82.19480 & 17.80520 \\
5 & 0.137152 & 82.19272 & 17.80728 \\
6 & 0.137592 & 81.85942 & 18.14058 \\
7 & 0.137615 & 81.86553 & 18.13447 \\
8 & 0.137625 & 81.86657 & 18.13343 \\
9 & 0.137637 & 81.85531 & 18.14469 \\
10 & 0.137638 & 81.85534 & 18.14466 \\
\hline
\end{tabular}

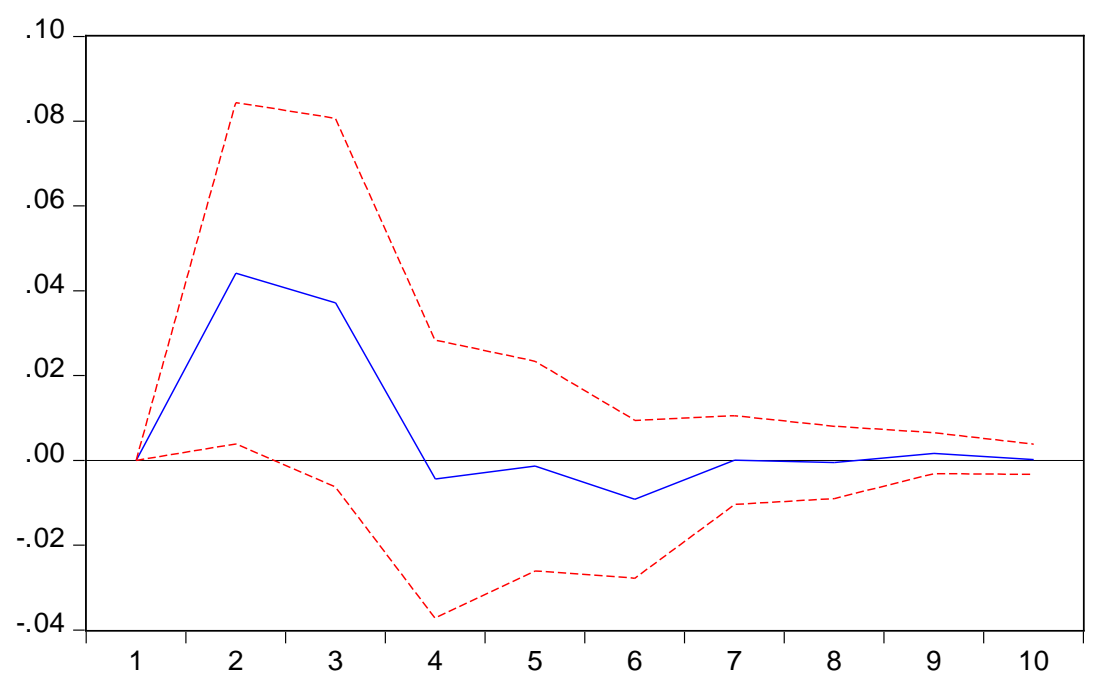

Figure 1. Response of LNPCHE to LNPGDP.

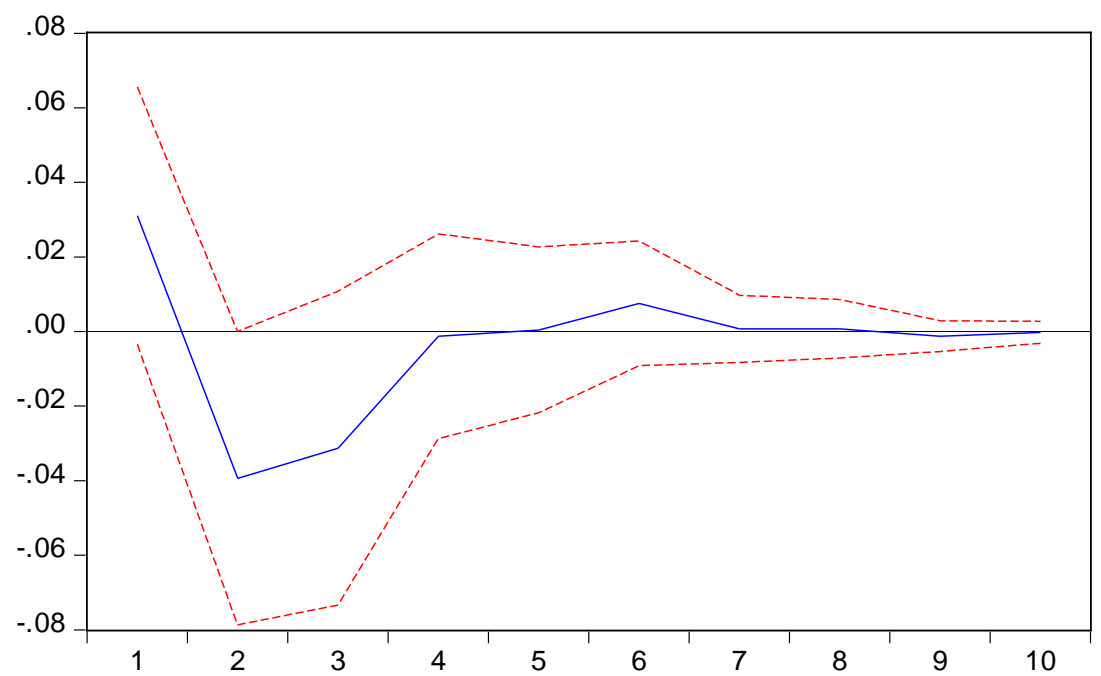

Figure 2. Response of LNPGDP to LNPCHE.

own shocks. In the second period, PCHE is influenced by GDP series at the rate of $11.86 \%$. This percentage increasing reaches $18.14 \%$ respectively until the sixth 
period. On the other hand in short term, the fluctuation of PCGDP is influenced by PCHE and is gradually decreased in the long run. Therefore, it can be seen that the long-term growth of GDP has a weak impact on PCHE. The causality test cannot reject the null hypothesis because PCHE does not Granger cause economic growth. Thus, here assumed to be unnecessary show the variance GDP decomposition.

\section{Discussion}

This paper was aimed to analyze the relationship between PCHE and economic growth in Mongolia using VAR model. Annual data from 1993 to 2018 was studied. First analysis was unit root test, which was used to define whether the two variables are stationary for co-integration test and VAR model. The results showed that level P-values of two variables were higher than 0.05 in levels and after transformed in first difference of P-values were lower than 0.05 . Therefore, two variables could be used as necessary conditions for establishing VAR model. There was a correlation between PCHE and PGDP with obvious one-way Granger causality. In addition, economic growth is one of the causes of PCHE in Mongolia. The co-integration result suggested that a long-term relationship between PCHE and PCGDP did not exist in the case of Mongolia. With an increase of $1 \%$ in the ratio of GDP, the ratio of investment to health expenditure was increased by $3.80 \%$ and $0.93 \%$, which showed that PGDP has significant influence on PCHE in the short term. By Engle-Granger estimation found that income elasticity of health expenditure of 0.93 . Thus, the health has been classified at necessity good. There exists a causal relationship between PGDP and PCHE in Mongolia, therefore, it is strongly recommended to increase the income level of population, improve health education, and provide the quality of healthcare facilities. Despite the low investment in the health sector as population growth, GDP growth and investment in human and physical capital increase the PCHE [41]. In Mongolia, health services are funded by three main means: central state budget, SHI, and out-of-pocket payments (OOP). Mongolian total health expenditure between 1995 and 2018 increased from 20 million dollars to 368.3 million dollars. Although annual health expenditure and health care financing are increasing, it is only $70 \%$ of the demand for PCHE [41]. Thus, it can be argued that the increased healthcare costs may be attributable to excessive and unnecessary healthcare financing. Consequently, it appears that the increase in health care expenditures does not influence the economic growth. In this case, according to research findings, we suggest that implementing relevant policies and strategies for health spending will not meaningfully influence the economic growth. However, by improving the health system, efforts should be made to improve health outcomes such as life expectancy and improving the living quality of overall population.

In 1990s, OOP was for only a small part of the total health expenditure, but by 2014 (currently $38 \%$ of the total), the proportion is $42 \%$ [42]. Compared with 
other countries in the Asia and Pacific region, this proportion (42\%) is very high, which is $17 \%$ higher than the level recommended by WHO [43]. Since the launch of social health insurance (SHI) in 1994, the role of social security fund in health financing has been declining. The role of medical insurance in public health financing is generally declining and unstable, which leads to the increase of OOP. Thus, governments and policymakers need to develop and implement policies to regulate health expenditures by reducing OOP.

On February 16, 2016, the state great rural of Mongolia issued the sustainable development vision 2030 as an important national planning guide, that the goal of improving health protection in the "Outline" refers to the reduction of the proportion of personal health expenditure to total health expenditure from the current $38 \%$ to around $25 \%$. The government increased investment in health care and reduced the personal health burden of residents. But increasing health financing is not a guarantee of population health. It is necessary to improve the level of health financing and steadily promote the economic growth of Mongolia to ensure the sustained economic growth of Mongolia, not only to improve the productivity of the supply side, but also to expand the market demand. In Mongolia, only $17 \%$ of total health expenditures are spent on primary care or public health services, which is less than $30 \%$ recommended by the WHO and Asian Development bank [44]. Therefore, Health funding should be allocated appropriately and efficiently.

\section{Conclusion}

The result of Granger causality test indicated a unidirectional impact that PGDP Granger causes PCHE in Mongolia. Economic elasticity was $0.93 \%$. In the short term, economic growth will promote health expenditure. Most research results showed that direction of causality depends on the income level of the countries, while two-way causality was only in higher-income countries. We also found that health expenditure does not cause economic growth in the case of middle and low-income. The result for VAR model showed that the positive shock of economic growth on PCHE existed in over the $1-3$ years, but in the long term, the response was gradually eradicated on health expenditure growth by impulse response function. The contribution influence of PGDP on PCHE has increased from $0 \%$ to $18.14 \%$ in the short-term by six periods in the variance decomposition test. While PCHE did not significantly influence economic growth. These results matched with the previous study of J. Rana [45]. However, increased PCHE did not lead to economic growth, Mongolia tried to increase investment, decrease unemployment rate and to support the health education of the rural and urban resident, these can be possible to have economic development. But economic growth in each country does not represent an increase in PCHE. The growth of GDP per capita represents the improvement of residents' income level, which improves the people's ability to pay for health care and medical expenses lead to the increase of per capita health expenses. While reaching the loss of ac- 
tivities due to a lack of funding for the health sector, there was a huge amount of balance in insurance fund which shows the disadvantages of the current insurance system of Mongolia. Therefore, there is a need to modify the policies of health in Mongolia which would ultimately result in the low expeditor of health. Meanwhile, there is a need to improve the health insurance system and develop the private health insurance system. By doing all these initiatives, Mongolia will be able to have a balance between PCHE and economic growth.

\section{Conflicts of Interest}

The authors declare no conflicts of interest regarding the publication of this paper.

\section{References}

[1] Newhouse, J. (1977) Medical Care Expenditure: A Cross-National Survey. Journal of Human Resources, 12, 115-125. https://doi.org/10.2307/145602

[2] Barro, R. (1995) Economic Growth. McGraw-Hill, Inc., New York.

[3] Kleinman, E. (1974) The Determinants of National Outlay on Health. In: Perlman, M., Ed., The Economics of Health and Medical Care, Wiley Press, Hoboken, 66-88.

[4] Hansen, P. and King, A. (1996) The Determinants of Health Care Expenditure: A Cointegration Approach. Journal of Health Economics, 15, 127-137. https://doi.org/10.1016/0167-6296(95)00017-8

[5] Gerdtham (1992) An Econometric Analysis of Health Care Expenditure: A Cross-Section Study of the OECD Countries. Journal of Health Economics, 11, 63. https://doi.org/10.1016/0167-6296(92)90025-V

[6] McCoskey, S. and Selden, T. (1998) Health Care Expenditures and GDP: Panel Data Unit Root Test Results. Journal of Health Economics, 17, 369-376. https://doi.org/10.1016/S0167-6296(97)00040-4

[7] Carter, R.A.L. and Blomqvist, A.G. (1997) Is Health Care Really a Luxury? Journal of Health Economics, 16, 207-229. https://doi.org/10.1016/S0167-6296(96)00534-6

[8] Liao, Y., Huang, X. and Luo, L. (2014) Analysis on Influencing Factors of per Capita Health Expenditure in Hainan. Chinese Health Economics, 33, 58-60.

[9] Development Center of Health (2019) Statistical Yearbook of Mongolia.

[10] National Statistics Office of Mongolia (2019) Statistical Information Database.

[11] Dorjdagva, J. (2016) Catastrophic Health Expenditure and Impoverishment in Mongolia. International Journal for Equity in Health, 15, Article No. 105.

[12] Chen, G., Huo, J. and Feng, Q. (2017) Empirical Study on the Factors Affecting China's per Capita Health Expenditure. Chinese Prices, 4, 86-88.

[13] Haldar, S. (2008) Effect of Health Human Capital Expenditure on Economic Growth in India: A State Level Study. Asia-Pacific Social Science Review, 8, 1-10. https://doi.org/10.3860/apssr.v8i2.785

[14] Bukenya, J. (2009) Do Fluctuations in Health Expenditure Affect Economic Growth? The Open Economics Journal, 2, 31-87.

[15] Sanmi, O. and Bakare, A.S. (2011) Health Care Expenditure and Economic Growth in Nigeria: An Empirical Study. Journal of Emerging Trends in Economics and Management Sciences, 2, 83-87. 
[16] Emadzadeh, M., Sameti, M., et al. (2011) The Relationship between Health Expenditure and Economic Growth. Journal of Healthcare Information Management, 87, 918-928.

[17] Mojtahed, S. and Avadipour, A. (2004) Investigation of the Effects of Health Expenditure on Economic Growth (Case Study of Developing Countries). Iranian Journal of Economic Research, 19, 31-54.

[18] Ogundipe, M.A. (2011) Health Expenditure and Nigerian Economic Growth. European Journal of Economics, Finance and Administrative Sciences, 30, 125-129.

[19] Tieguhong, J.C. and Piabuo, S.M. (2016) Health Expenditure and Economic Growth: A Review of the Literature and an Analysis between the Economic Community for Central African States CEMAC and Selected African Countries. Health Economics Review, 7, 23.

[20] Li, Y.B., et al. (2018) Relevance Research between per Capita Health Expenditure and Economic Growth in China. Chinese Health Resources, 21, 111-115.

[21] Chen, H., Huang, Y. and Chen, Z. (2005) The Research of Relationship between Health Expenditures and Economic Increase of China. Forecasting, 24, 24-27.

[22] Zhou, Z. (2006) Discussion on the Growth of Health Expenditure and the Law of Economic Development in China and OECD Countries. Chinese Journal of Hospital Administration, 26, 26-29.

[23] He, B. and Liu, H. (2010) Research on the Relationship between Health Investment and Economic Growth in China Based on PVAR Model. Chinese Health Economics, 29, 26-29.

[24] Cetin, M., et al. (2018) The Impact of Economic Growth, Energy Consumption, Trade Openness, and Financial Development on Carbon Emissions: Empirical Evidence from Turkey. Environmental Science and Pollution Research, 25, 36589-36603. https://doi.org/10.1007/s11356-018-3526-5

[25] Wang, K. (2011) Health Care Expenditure and Economic Growth: Quantile Panel-Type Analysis. Economic Modelling, 28, 1536-1549. https://doi.org/10.1016/j.econmod.2011.02.008

[26] Bedir, S. (2016) Healthcare Expenditure and Economic Growth in Developing Countries. Advances in Economics and Business, 4, 76-86. https://doi.org/10.13189/aeb.2016.040202

[27] Sghari, M.B.A. and Hammami, S. (2013) Relationship between Health Expenditure and GDP in Developed Countries. IOSR Journal of Pharmacy, 3, 41-45. https://doi.org/10.9790/3013-0343041-45

[28] Zahonero, J. and Esteve, E. (2014) Testing the Long-Run Relationship between Health Expenditures and GDP in the Presence of Structural Change: The Case of Spain. Applied Economics Letters, 14, 271-276. https://doi.org/10.1080/13504850500425196

[29] Philips, P. and Peter, C. (1988) Testing for a Unit Root in Time Series Regression. Biometrika, 75, 335-346. https://doi.org/10.1093/biomet/75.2.335

[30] Nie, L. (2013) Empirical Analysis on the Relationship of Total Health Expenditure, Physical Capital Investment and Economic Growth. Chinese Health Economics, 32, 58-60.

[31] Granger, C.W.G. and Engle, R.F. (1987) Co-Integration and Error Correction: Representation, Estimation, and Testing. Econometrica, 55, 251-276. https://doi.org/10.2307/1913236

[32] Granger, C.W.J. and Newbold, P. (1987) Spurious Regressions in Econometrics. 
Journal of Economics, 2, 111-120. https://doi.org/10.1016/0304-4076(74)90034-7

[33] Sims, C.A. (1980) Macroeconomics and Reality. Econometrica, 48, 1-48. https://doi.org/10.2307/1912017

[34] Lu, G.M. (2012) China's Short-Term International Capital Flow-Analysis of Triple Motivation Based on Monthly VAR Model. Journal: Studies of International Finance, 4, 61-68.

[35] Granger, C.W. (1969) Investigating Causal Relations by Econometric Models and Cross-Spectral Methods. Econometric, 37, 424-438. https://doi.org/10.2307/1912791

[36] Koehler, A.B. (1988) A Comparison of the Akaike and Schwarz Criteria for Selecting Model Order. Applied Statistics, 37, 187-195. https://doi.org/10.2307/2347338

[37] Rafiq, S., Salim, R. and Bloch, H. (2009) Impact of Crude Oil Price Volatility on Economic Activities: An Empirical Investigation in the Thai Economy. Resources Policy, 34, 121-132. https://doi.org/10.1016/j.resourpol.2008.09.001

[38] Johansen, S. and Juselius, K. (1990) Maximum Likelihood Estimation and Inference on Cointegration with Applications to the Demand for Money. Oxford Bulletin of Economics and Statistics, 52, 169-210.

[39] Dickey, D.A. and Fuller, W.A. (1979) Distribution of the Estimators for Autoregressive Time Series with a Unit Root. Journal of the American Statistical Association, 74, 427-431. https://doi.org/10.2307/2286348

[40] Mehdi, S. (2013) The Effect of Health Expenditure on Economic Growth in Iran. African Journal of Business Management, 7, 3972-3976.

[41] Bayarsaikhan, B. (2006) Estimation of Mongolia in Gross Domestic Product (GDP) and Health Care Expenditure (HCE) per Capita by the Augmented Solow Model. Mongolian Health Science, 2, 32-40.

[42] Byambaa, M. (2019) Reducing Out-of-Pocket Payments for Health in Order to Achieve Universal Health Coverage in Mongolia.

[43] Mongolian Public Health Professionals of Association (2011) Informal Payments in Health Sector in Mongolia.

[44] WHO (2018) Public Spending on Health: A Closer Look at Global Trends.

[45] Rana, R., Alam, K. and Gow, J. (2019) Health Expenditure and Gross Domestic Product: Causality Analysis by Income Level. International Journal of Health Economics and Management, 20, 55-77. 